\title{
EXPLORANDO AS ESCALAS PENTATÔNICAS NA GUITARRA ELÉTRICA
}

Alexsander VANZELA

Licenciado em Música com habilitação em Guitarra pela UNINCOR em Três Corações/MG (2011), pós-graduado em Educação Musical pela Universidade Cândido Mendes UCAM - Prominas (2012), atualmente é professor de guitarra elétrica no Conservatório Estadual de Música “Lobo de Mesquita” em Diamantina-MG. www.alexvanzela.com, email: alexvanzela@gmail.com

\section{Recebido em: 21/05/2014 - Aprovado em: 15/09/2014 - Disponibilizado em: 15/12/2014}

\section{Resumo:}

Sendo professor de guitarra há algum tempo, vi a necessidade de escrever este artigo que fala um pouco sobre as escalas que se iniciam nos estudos intermitentes do mundo da guitarra elétrica. Escalas essas onde se aplicam e podem se basear na maioria dos solos mais conhecidos como Another brick in the Wall do Pink Floyd ou Always for you, always for me de Joe Satriani entre tantos outros. Trata-se da Escala Pentatônica seguida bem de perto da escala Penta Blues e que faço uma miscelânea juntando-as com as escadas do Modo Grego. Enfim, essas as escalas que acho as mais indicadas para o início dos estudos da guitarra elétrica, juntamente com as técnicas que fazem com que esse mundo sejam mais envolvente e indiscutivelmente versátil perante aos outros instrumentos, contudo não menosprezando os outros instrumentos que existem, há um amor intrínseco pelos amantes das seis cordas, seja pela beleza, seja pela versatilidade, seja pela qualidade timbrística, pela aplicação, enfim as aplicações são diversas para os guitarristas.

Palavras Chave: Pentatônica, Penta Blues, Modos Gregos, Técnicas de Guitarra e Guitarra Elétrica.

\begin{abstract}
Being a guitar teacher for a while, I saw the need to write this article that talks a little about the scales that start flashing studies in the world of electric guitar. These scales where they apply and may be based on most soils known as Another Brick in the Wall Pink Floyd or Always for you, always for me Joe Satriani among others . This is the Pentatonic scale followed closely Penta Blues scale and do a smorgasbord joining them with the stairs from the Greek mode. Anyway, these scales which I think the most suitable for the early studies of the electric guitar, along with the techniques that make this world more engaging and versatile arguably before the other instruments, but not belittling the other instruments that exist, there an intrinsic love for lovers of six strings for the beauty, is its versatility , is the timbre quality, the application, the applications are finally different for guitarists .
\end{abstract}

Keywords: Pentatonic, Blues Scale, Modos Gregos, Guitar Techniques e Eletric Guitar. 


\section{INTRODUÇÃO}

Os estudos sobre escalas musicais são importante para os músicos, em geral aqueles que utilizam do solo para complementar sua música como os guitarristas que buscam uma performance de acordo com os estilos, trata-se de ter um "groove" ou uma "pegada" para determinado estilo. Em estudos sobre escalas para os aspirantes a guitarristas, existe aquela que é muito utilizada, talvez a mais utilizada, que é a Escala Pentatônica.

Em alguns textos há indícios que foi na China que se deu o seu início, onde um músico que reuniu as divisões melódicas propostas por Pitágoras e utilizando seus intervalos harmônicos, achou-se um grupo de cinco notas dividindo em maior e menor (immusicstation.blogspot.com.br).

As Escalas Pentatônicas foram muito utilizadas pelos escravos Americanos trazidos da África, onde cantavam em seu início os cantos sagrados (Spirituals) suas dores e seus desejos de liberdade, mais tarde originou o Blues onde a Escala Pentatônica está presente com o aumento de uma nota, o quinto grau menor (b5), que ficou conhecida como a Penta Blues ou Blue Scale.

Chamada também como Escala Hexatônica por possuir seis notas, a Penta Blues foi um grande achado para os escravos (músicos) americanos, onde se encaixava perfeitamente suas canções e a cultura afro- americana era introduzida musicalmente no Mississipi, Alabama, Lousiana, Georgia.

A Escala Pentatônica se desempenhou um papel importantíssimo no blues, trazendo a facilidade de cinco notas soarem com tanta beleza que ela foi tendo um papel muito importante e que com o aumento de uma nota surge a Penta Blues trazendo à tona toda aquela dor e tristeza nos momentos em que a música é tocada mais lentamente, mas quando se coloca a velocidade e destreza aliada a músicos com habilidades surpreendentes, o ritmos de Blues mais tarde contribuiria com o Rock, Jazz e Country.

O fato de haver vários escravos oriundos de diversas partes da África, nos Estados Unidos houve uma grande produção musical no Blues, onde alguns cantavam as dores e os sofrimentos de serem arrancados de suas famílias e de seu país de origem, outros cantavam as alegrias de viverem em contato com os seus, outros porém cantavam e dançavam com intuito ou apelo sexual.

Quando a guitarra elétrica chegou ao meio musical por volta dos anos 50 e 60, houve um aumento sonoro incrível, porque quando uma banda formada por bateria, guitarra acústica e piano ou sax tocavam juntos, a guitarra acústica não "aparecia no conjunto da obra", mas quando houve a inclusão da guitarra elétrica, tudo mudou, o Blues se fortificou e grandes músicos que já utilizaram da escala pentatônica e da escala 
penta blues como escalas diretamente ligadas a esse ritmo fizeram com que músicos que não eram adeptos ao blues começassem a olhar com Outros instrumentos foram utilizados como a gaita, o piano e instrumentos de sopro como o trompete e o saxofone entre outros, foram de grande valia para o Blues, utilizando da mesma escala.

Os músicos de outros estilos, foram também adicionando aos seus estilos essas escalas, surgindo pós jazz e rock, o Fusion. Os guitarristas porém diversificam os estilos e utilizam variadas escalas para obterem o melhor resultado e a Escala Pentatônica é uma dessas.

\section{Escala Pentatônica Menor}

O desenho da escala pentatônica menor é usada com muita frequência em solos de blues, o que contribui para o caráter dúbio que este tipo de escala possui. A escala de lá menor (Am) que é a escala relativa menor da escala maior de dó $(\mathbf{C})$, possui todas as notas desta última escala e como pode ser chamada também de Escala Menor Natural (Am) ou Modo Eólio.

Tomemos como exemplo a escala de lá, uma escala menor, que contém todas notas naturais sem nenhum acidente, ou seja, sem sustenido (\#) ou bemol (b):

\begin{tabular}{|c|c|c|c|c|c|c|c|}
\hline I & II & III & IV & V & VI & VII & VIII \\
\hline A & B & C & D & E & F & G & A \\
\hline
\end{tabular}

A pentatônica menor é obtida pela eliminação dos II e do VI graus e pode também ser utilizada em substituição a escala diatônica menor em solos e improvisos.

\begin{tabular}{|l|c|c||c|c|c|}
\hline I & III & IV & V & VII & VIII \\
\hline A & C & D & E & G & A \\
\hline \multicolumn{2}{|l|}{$1.1 / 2$ tom } & 1 tom & 1 tom & \multicolumn{1}{|l|}{$1.1 / 2$ tom } & \multicolumn{1}{|l|}{ tom } \\
\hline
\end{tabular}

\section{Escala Pentatônica Maior}

Agora tomemos como exemplo a escala de lá maior (A), que diferente da escala menor, contém os acidentes sustenidos (\#) nos III, VI e VII graus.

\begin{tabular}{|c|c|c|c|c|c|c|c|}
\hline I & II & III & IV & V & VI & VII & VIII \\
\hline A & B & C\# & D & E & F\# & G\# & A \\
\hline
\end{tabular}

Neste caso, a escala pentatônica maior é obtida pela eliminação dos IV e do VII graus obtendo cinco outras notas para surgir então a Escala Pentatônica Maior, que neste caso é a escala pentatônica de lá maior.

\begin{tabular}{|c|c|c|c|c|c|}
\hline I & II & III & V & VI & I \\
\hline A & B & C\# & $E$ & F\# & A \\
\hline \multicolumn{2}{|c|}{1 tom } & & & & \\
\hline
\end{tabular}

Quando utilizamos as escalas para exercícios, vejo que é necessário ir além, nos surpreender com novas tentativas e isso é claro, consiste em acertos e erros, mais tentar 
outras possibilidades sonoras para a utilização musical com qualidade e bom gosto.

Ao verificar que a pentatônica menor possui cinco notas (vejamos a escala de Am) A C D E G, damos início a um ciclo que gira em torno dessas cinco notas. Irão surgir cinco desenhos distintos com as mesmas notas, para uma melhor ergonomia, utilizando todo o braço da guitarra e ter variações timbrísticas simplesmente fantásticas, assim posso dizer que esse primeiro modelo da pentatônica, chamando-o de Penta 1 e terá esse desenho:

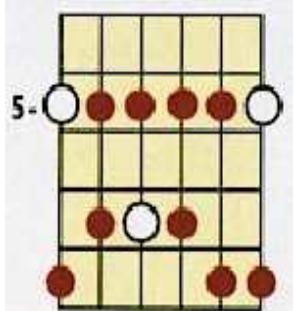

Penta 1

Quando inicio em dó (C), as notas terão a mesma sequência, mas com o início em dó as notas seguintes serão ré (D), mi (E), sol $(\mathbf{G})$ e lá $(\mathbf{A})$ e teremos a Penta 2.

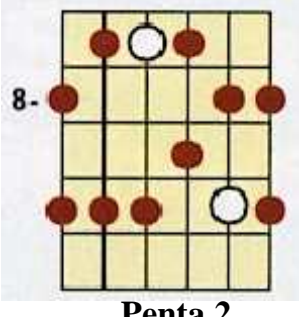

Penta 2

Partindo da nota ré (D), D E G A C, Penta 3.

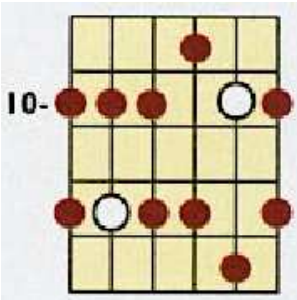

Penta 3

Partindo da nota mi (E), E G A C D, Penta 4.

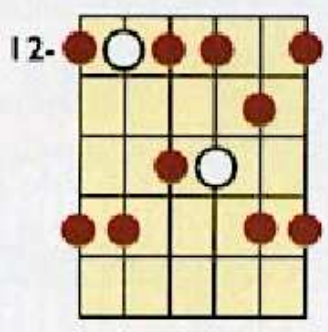

Penta 4

Partindo da nota sol (G), G A C D E, Penta 5.

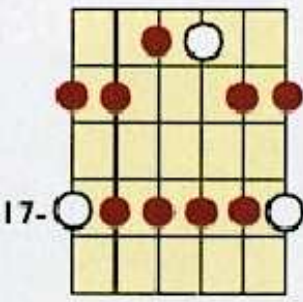

Penta 5

O primeiro passo para "apimentar" a pentatônica é a utilização do Blue Note, que é a bemol cinco (b5) e ficará assim a penta blue de lá menor (Am): A C D Eb E G
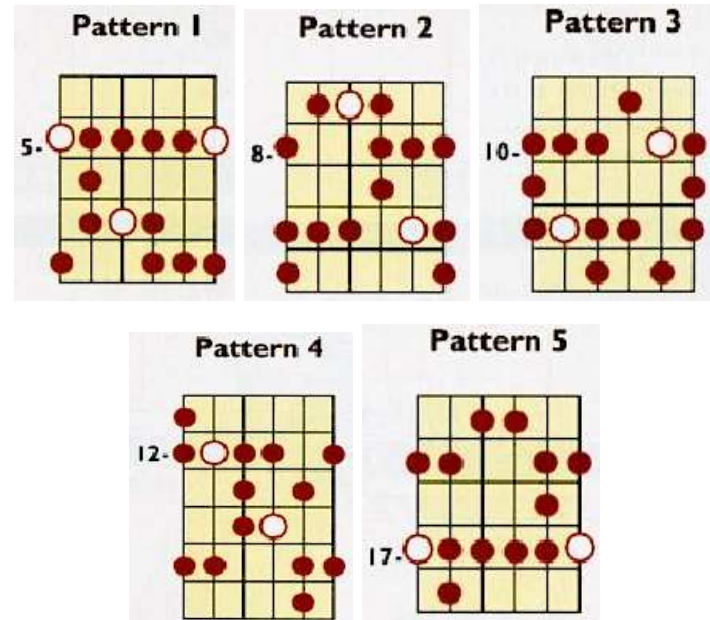

Agora chegamos a parte interessante, sabendo que existe os Modos Gregos, vamos unir os desenhos das cinco pentatônicas e consequentemente das cinco penta blues nos cinco Modos na sequência das pentas, Eólio (A), Jônio (C), Dório (D), Frígio (E) e Mixolídio (G). 
Notas no Modo Eólio, (Am Eólio)

\begin{tabular}{|l|l|l|l|l|l|l|l|l|l|}
\hline Graus & 1 & 2 & 3 & 4 & b5 & 5 & 6 & 7 & 8 \\
\hline $\begin{array}{l}\text { Modo } \\
\text { Eólio }\end{array}$ & A & B & C & D & & E & F & G & A \\
\hline
\end{tabular}

Escala Pentatônica, tom lá menor (Am)

\begin{tabular}{|l|l|l|l|l|l|l|l|l|l|}
\hline Graus & 1 & 2 & 3 & 4 & b5 & 5 & 6 & 7 & 8 \\
\hline Pentatônica & A & & C & D & & E & & G & A \\
\hline
\end{tabular}

Escala Penta Blues

\begin{tabular}{|l|l|l|l|l|l|l|l|l|l|}
\hline Graus & 1 & 2 & 3 & 4 & b5 & 5 & 6 & 7 & 8 \\
\hline $\begin{array}{l}\text { Penta } \\
\text { Blue }\end{array}$ & A & & C & D & Eb & E & & G & A \\
\hline
\end{tabular}

Somando as três escalas

\begin{tabular}{|l|l|l|l|l|l|l|l|l|l|}
\hline Graus & $\mathbf{1}$ & $\mathbf{2}$ & $\mathbf{3}$ & $\mathbf{4}$ & $\mathbf{b 5}$ & $\mathbf{5}$ & $\mathbf{6}$ & $\mathbf{7}$ & $\mathbf{8}$ \\
\hline & A & B & C & D & Eb & E & F & G & A \\
\hline
\end{tabular}

Obtemos assim este desenho no braço da guitarra, Shape da Penta 1 em lá menor (Am)

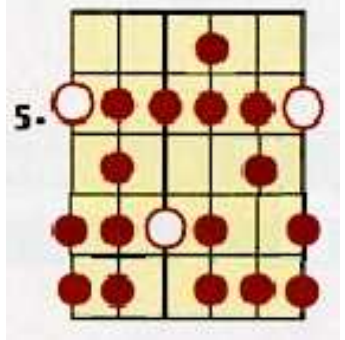

Agora vamos entender o que acontece e o que podemos fazer utilizando essa escala híbrida. Essa escala pode ser utilizada em todos os estilos musicais, mas é preciso ter cuidado para não fazer repouso em notas que não são interessantes, é o caso do b5 (Eb).
Pensando em uma sonoridade Blues, o b5 vem ao encontro desta escala, também aqui é preciso utilizar com cuidado para a utilização daquelas notas "a mais" do que é necessário para se tocar/soar Blues.

Outro estilo é o Jazz e aqui ela é perfeita, podemos até utilizar os cromatismos que ainda faltam (olhando o shape), pois existe uma consistência muito interessante no fato de que o jazz utiliza o cromatismo como forma de "abrilhantar" a sonoridade, assim a utilização desse método é muito bem vindo.

Olhando as notas da $3^{\mathrm{a}}$ corda, temos si (B), dó (C), ré (D) e mi bemol (Eb). Neste caso há a possibilidade de inserir um ré bemol (Db) para ter um grande cromatismo e com um Slide, dar um "toque" especial no solo. Ao reparar as cordas si $(\mathbf{B})$ e $\mathrm{mi}(\mathbf{E}), 1^{\mathrm{a}}$ e $2^{\mathrm{a}}$ respectivamente, podemos também incluir o cromatismo e ter uma sonoridade atraente para o jazz.

\section{TÉCNICAS}

As técnicas auxiliam a performance do guitarrista, onde elas podem dar nuances e desenvolver uma sonorização especial, tudo aliado ao timbre.

Os guitarristas utilizam técnicas como Pull Off (P), Hammer On (H), Slide (S), Bend (B), Reverse Bend (RB), Tapping (T), entre outros. Vibratos e acentuações são 
comumente usadas para enfatizar o solo ou a música em questão.

Então, aliando as escalas Pentatônicas, Penta Blues e Modos Gregos com as técnicas, o guitarrista enfim poderá ter uma "carta na manga" para sua música

Em um trecho da música Always with me, always with you de Joe Satriani existe algumas técnicas como Pull Off (P), Slide (S) e vibrato ( ) empregadas e fazendo um cromatismo descendo de sol (G) até ré sustenido (D\#), logo após um Pull off de ré sustenido (D\#) para mi (E), terminando com um vibrato em dó sustenido (C\#) e posteriormente um Slide (sl) na mesma nota.

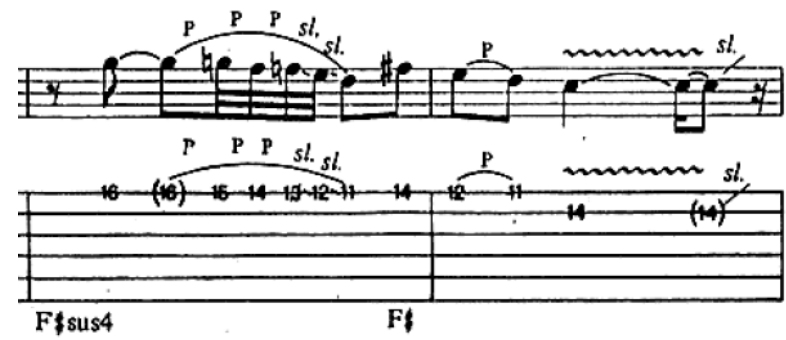

Outro trecho de um solo muito conhecido utilizando as escalas pentatônicas e modos é a parte de Another Brick in the wall

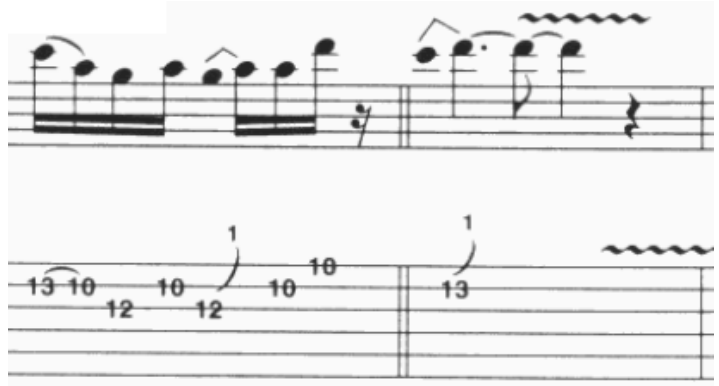

onde David Gilmour inicia este $l i c k^{1}$ o solo com um pull off ${ }^{2}$, em seguida ele trabalha com dois bends ${ }^{3}$ e terminando com um trêmulo ${ }^{4}$.

\footnotetext{
${ }^{1}$ Lick é um pedaço de um solo
}

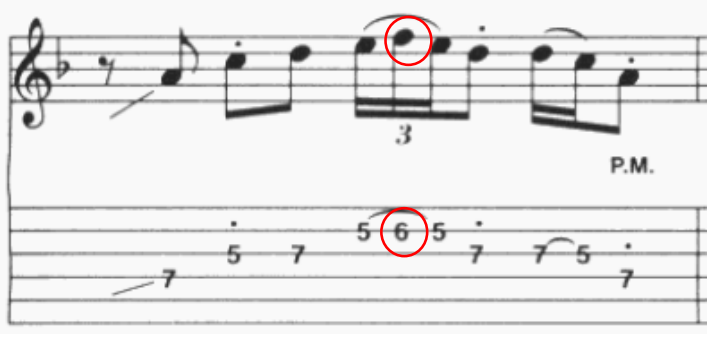

Neste outro trecho o guitarrista inicia o lick com um Slide 5 e depois há duas notas ligadas, um mi e um fá, sendo este (círculado) fazendo parte da escala menor, ou seja, o guitarrista utilizou a pentatônica mais a escala menor.

Em outra música, o guitarrista utiliza das cordas soltas para fazer uso da pentatônica na guitarra base e tendo uma sonoridade inigualável, em outras palavras ele conseguiu mesclar um acorde com a utilização da pentatônica como é mostrado abaixo:

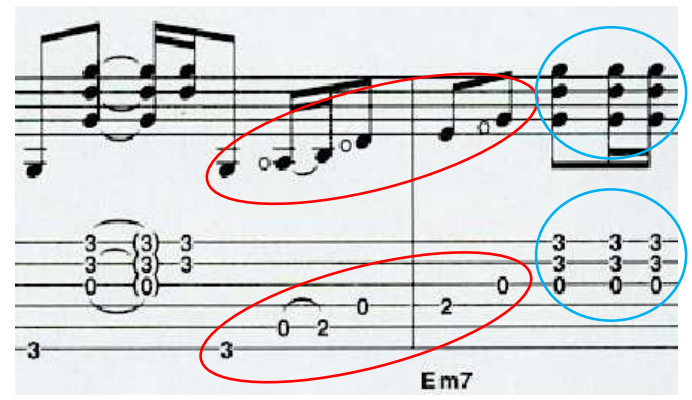

No círculo em vermelho está a pentatônica feita em cima do acorde de Mi menor com sétima $(\mathbf{E m 7})$ e em seguida no círculo em azul, o acorde de Sol (G).

\footnotetext{
${ }^{2}$ Pull Off é quando uma nota é tocada e a segunda é ligada a ela apenas com a força dos dedos da mão esquerda.

${ }^{3}$ Bends técnica onde se levanta a corda com um dedo da mão esquerda elevando a nota em 1/2, 1 ou mais tons.

${ }^{4}$ Trêmulo é quando a corda é vibrada utilizando a mão esquerda, fazendo vários micro-bends.

${ }^{5}$ Slide é quando desliza o dedo em uma corda, subindo ou descendo a escala.
} 
Em outro seguimento musical, Eddie Van Halen utiliza além de técnicas como o Bend e vibrato, a pentatônica com o Blue Note.

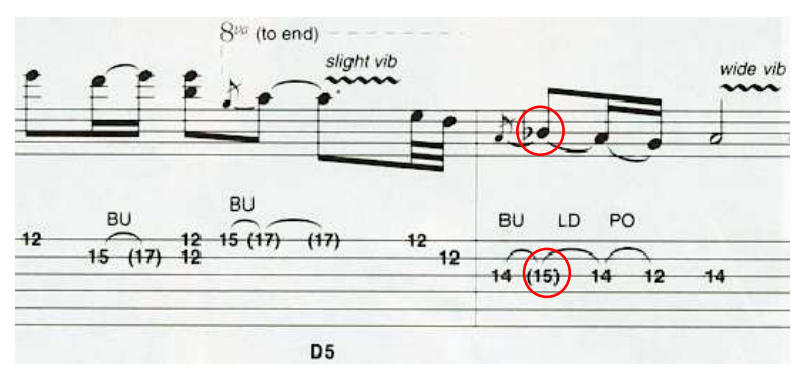

A nota no circulo vermelho é o blue note, onde ele utiliza um Bend (BU), um Reverse Bend (LD) e posteriormente um Pull Off (PO), terminando num vibrato.

As técnicas empregadas fazem com que os guitarristas mostrem sua virtuosidade em empunhar as seis cordas, pois se tratando de um instrumento que intuitivamente atrai jovens e pode ser mudado de formato e muitas vezes adicionado outras cordas, a guitarra elétrica tem assumido cada vez mais parte de um contexto musical onde se encontra, seja no ritmo $\mathrm{A}$ ou $\mathrm{B}$, mas quando bem executada e tendo a oportunidade de haver um solo onde a guitarra elétrica aparece, é um convite a vivenciar novas tendências musicais com texturas nobres.

"Quando Hendrix fazia seu show, fundia cucas e aterrorizava o público".(HENDERSON, p. 85, 1993)

\section{Conclusão}

É notório que a utilização das Escalas Pentatônicas é um referencial didático adotado pela maioria dos guitarristas para passarem seu conhecimento a outros.

Os guitarristas por sua vez à utilizam a fim de obterem uma visualização do braço da guitarra, suas notas e digitações. A partir da escala pentatônica a penta blues toma força e em alguns casos os Modos entrarão em ação.

É claro que não existe somente essas três escalas citadas neste artigo, mas trata-se apenas de uma visão simplificada a partir do ponto de vista de um professor de guitarra, onde é claro a facilidade da utilização em foco às demandas sonoras provenientes de temas cotidiano.

A música está presente em tudo, bem como a improvisação é um passo para músicos expressarem seus sentimentos perante a uma situação musical.

Portanto, vejo que como educadores e levando o conhecimento musical à aqueles que anseiam a se tornarem músicos, utilizando a guitarra elétrica como seu instrumento profissionalizante, passar os conhecimentos obtidos em anos de estudo de forma que o aluno entenderá com maior eficácia as lições a ele passada e se tornar realmente um músico.

\section{Referências}

HENDERSON, David. A vida de Jimi Hendrix. Dá licença que eu vou beijar o céu. Rio de Janeiro. Espaço e Tempo, 1993. 
http://immusicstation.blogspot.com.br/p/blues

-e-pentatonicas.html - acesso em 08/05/2014

Muggiati, Roberto, Blues da lama à fama.

Editora 34,1995

NEELY, B.; SCHROEDL, J. Chords \&

Scales for Guitar. Milwaukee: Hal Leonard

Corporation, 1997. 